\title{
4-Carboxyl-2,6-dinitrophenylazohydroxynaphthalenes tautomerism NMR re-explained and other methods verified
}

\author{
Silvia Hristova ${ }^{1}$, Silvia Angelova ${ }^{1}$, Poul Erik Hansen ${ }^{2} \&$ Liudmil Antonov ${ }^{1, *}$ \\ ${ }^{1}$ Institute of Organic Chemistry with Centre of Phytochemistry, Bulgarian Academy of Sciences, \\ Sofia 1113, Bulgaria \\ ${ }^{2}$ Roskilde University, Department of Science and Environment, DK-4000, Roskilde, Denmark
}

\begin{abstract}
In two consecutive studies the tautomerism in 4-((2-hydroxynaphthalen-1-yl)diazenyl)-3,5dinitrobenzoic acid and the structurally similar 1-((2-nitrophenyl)diazenyl)naphthalen-2-ol has been considered from viewpoint of theoretical chemistry, UV-Vis spectroscopy and NMR. Although the theoretical data (at M062X level) show that both compounds exist only as a keto tautomer, the experiment proves existence of the enol form. The difference in the results obtained by UV-Vis spectroscopy and NMR requires a deeper consideration and verification of the NMR approach, which is based on using model compounds to provide the NMR signal pattern of individual tautomers.
\end{abstract}

Keywords: 1-((2-nitrophenyl)diazenyl)naphthalen-2-ol, tautomerism, quantum chemistry, DFT, UV-Vis spectroscopy, NMR

\footnotetext{
${ }^{*}$ Corresponding authors: http://www.orgchm.bas.bg/ i2mp
} 


\section{Introduction}

In several papers Adegoke at al. described the synthesis of a series of 4-carboxyl-2,6dinitrophenylazohydroxynaphthalenes [1] and performed study of their tautomeric properties [2]. Recently we have shown [3] by theoretical calculations and by analysis of the existing crystallographic data of structurally similar compounds [4-8] that the structures of the enol and keto tautomers of 4-((2-hydroxynaphthalen-1-yl)diazenyl)-3,5-dinitrobenzoic acid as previously predicted by Adegoke are incorrect. In the same study [3] the tautomerism of 1-((2nitrophenyl)diazenyl)naphthalen-2-ol (1, Scheme 1) was investigated by using DFT calculations and UV-Vis spectroscopy. Although the theoretical results show that only the keto form (1k) should be presented in solution, the spectral data indicate a substantial amount of $1 \mathbf{e}$ in solution $(\sim 40 \%$ in isooctane).

In a very recent communication Lyčka discussed the tautomerism in $\mathbf{1}$ by using NMR [9]. Following the fact that the proton exchange between nitrogen and oxygen atoms in azodyes is fast on the NMR time scale and, thus, only one set of signals is always observed in NMR spectra (NMR data of both individual tautomers are not known) [10,11], he based the analysis on compounds $\mathbf{2}$ and $\mathbf{3}$ as models for the pure keto tautomer of $\mathbf{1}$. The assumption is based on previous NMR studies of the tautomerism of $\mathbf{2}$, showing that only $\mathbf{2 k}$ is presented in $\mathrm{CDCl}_{3}$ [12] and in DMSO-d ${ }_{6}$ [13]. This was also confirmed by the study of a 4-fluoroderivative [14]. Lycka mostly based his argument on one bond $\mathrm{NH}$ couplings. The question is if a compound like $\mathbf{2}$ in which the hydrogen bond acceptor is part of a five-membered ring is a good model for the naphthalene derivative. Lyčka [9] determined that the keto tautomer content in $\mathbf{1}$ as $95.1 \%$ in DMSO- $\mathrm{d}_{6}$, using 3 as a model for the pure keto tautomer. 


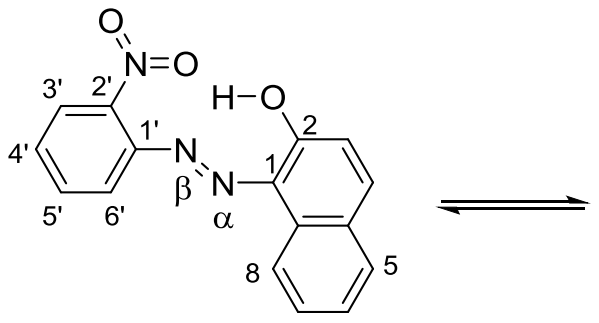

1e

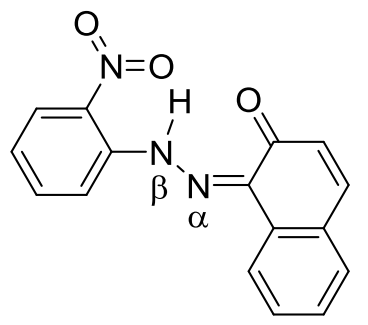

$1 \mathrm{k}$

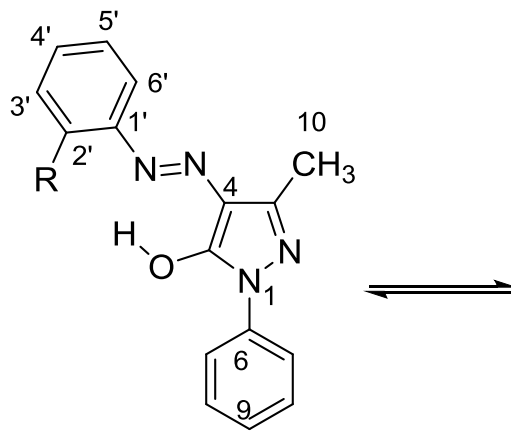

$\mathbf{e}$

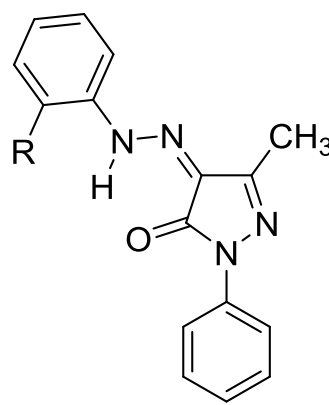

$\mathbf{k}$

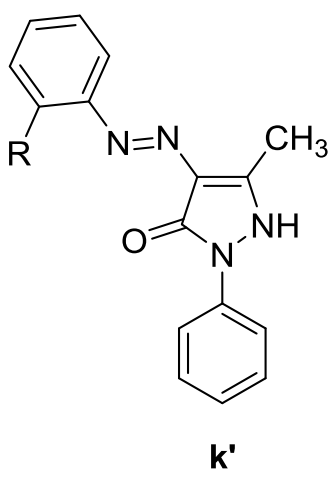

$\mathbf{k}^{\mathbf{\prime}}$

\section{$2 \mathrm{R}=\mathrm{H}$}

$3 \mathrm{R}=\mathrm{NO}_{2}$

Scheme 1. Structures discussed in the current note.

The investigation of the tautomerism in azodyes and related Schiff bases, existing as tautomeric mixtures, is a difficult task for NMR and UV-Vis spectroscopy, because in both cases the signals of the pure tautomers are unknown. The analysis includes either use of model compounds, approximating the spectral characteristics of the pure tautomers [10], or application of chemometric procedures based on resolution of overlapping bands [15]. Theoretical calculations can be of help in predicting parameters for the two tautomeric forms.

In the current communication we intend to verify the position of the tautomeric equilibrium in $\mathbf{3}$ by using theoretical calculations. The NMR spectra of the tautomers of $\mathbf{1}$ and $\mathbf{3}$ are predicted and compared in order to prove whether $\mathbf{3 k}$ can be used as a model of $\mathbf{1 k}$. In addition, the UV-Vis spectra of $\mathbf{1}$ in DMSO are measured and discussed in saturated solution, the 
same concentration as used by Lyčka [9], in order to avoid any suspicion for concentration effects affecting the tautomerism.

\section{Results and discussion}

In order to verify the approach used by Lyčka we need to answer two major questions: a) does compound $\mathbf{3}$ exist only as keto tautomer $\mathbf{3 k}$ ?; b) and then, are NMR characteristics of $\mathbf{3 k}$ suitable for determination of the tautomeric ratio in $\mathbf{1}$ ?

According to the theoretical calculations in the gas phase, the energy differences between the preferred rotamers of the keto and enol tautomers of 1-3 show clearly that the keto tautomers are more stable (Table 1, Figures S1-S2). The differences are especially large in the case of 2 and 3. As expected, in the latter additional stabilization is achieved by introducing electron acceptor substituent in the phenyl ring [16]. The transfer from gas phase to DMSO increases stability of the more polar keto tautomer. Having in mind that according to Lyčka [9] 1k is presented in 95.1\% in DMSO- $\mathrm{d}_{6}$, which corresponds to energy difference of $2.51 \mathrm{kcal} / \mathrm{mol}$, the stability of the keto forms in $2(7.61 \mathrm{kcal} / \mathrm{mol})$ and especially in $3(8.60 \mathrm{kcal} / \mathrm{mol})$ excludes the existence of the enol tautomer in solution. As shown in Table 1 and Figures S3-S4 the theoretical predictions are verified by using $6-31+\mathrm{G}^{* *}$ basis set.

Table 1. Calculated relative electronic energies $(\Delta \mathrm{E})$, sum of electronic and zero-point energies $(\triangle \mathrm{E}+\mathrm{ZPE})$, and Gibbs free energies for compounds $\mathbf{1 - 3}$, in $\mathrm{kcal} \mathrm{mol}^{-1}$.

\begin{tabular}{lrrrrrrrr}
\hline & \multicolumn{3}{c}{$\mathrm{M} 062 \mathrm{X} / \mathrm{TZVP}$} & & \multicolumn{3}{c}{$\mathrm{M} 062 \mathrm{X} / 6-31+\mathrm{G}(\mathrm{d}, \mathrm{p})$} \\
\cline { 2 - 3 } \cline { 7 - 9 } & $\Delta \mathrm{E}$ & $\Delta \mathrm{E}+\mathrm{ZPE}$ & $\Delta \mathrm{G}_{298}$ & & $\Delta \mathrm{E}$ & $\Delta \mathrm{E}+\mathrm{ZPE}$ & $\Delta \mathrm{G}_{298}$ \\
\hline gas phase & & & & & & & & \\
$\mathbf{1 k}$ & 0.00 & 0.00 & 0.00 & & 0.00 & 0.00 & 0.00 \\
$\mathbf{1 e}$ & 1.49 & 1.76 & 1.08 & & 1.40 & 1.01 & 1.32 \\
$\mathbf{2 k}$ & 0.00 & 0.00 & 0.00 & & 0.00 & 0.00 & 0.00 \\
$\mathbf{2 e}$ & 6.76 & 6.51 & 6.38 & & 6.08 & 5.72 & 5.14 \\
$\mathbf{2 k}$ & - & - & - & & 19.93 & 19.02 & 18.12 \\
$\mathbf{3 k}$ & 0.00 & 0.00 & 0.00 & & 0.00 & 0.00 & 0.00
\end{tabular}




\begin{tabular}{lrrrrrr} 
3e & 7.26 & 7.13 & 7.42 & 6.93 & 6.45 & 6.66 \\
3k' & - & - & - & 23.52 & 22.54 & 21.48 \\
& & & & & & \\
DMSO & & & & & & \\
$\mathbf{1 k}$ & 0.00 & 0.00 & 0.00 & 0.00 & 0.00 & 0.00 \\
$\mathbf{1 e}$ & 2.51 & 1.96 & 2.35 & 2.38 & 2.16 & 2.78 \\
$\mathbf{2 k}$ & 0.00 & 0.00 & 0.00 & 0.00 & 0.00 & 0.00 \\
$\mathbf{2 e}$ & 7.61 & 7.73 & 9.03 & 6.88 & 6.68 & 6.53 \\
$\mathbf{3 k}$ & 0.00 & 0.00 & 0.00 & 0.00 & 0.00 & 0.00 \\
$\mathbf{3 e}$ & 8.60 & 8.66 & 9.79 & 8.29 & 7.95 & 8.24 \\
\hline
\end{tabular}

The GIAO (Gauge-Independent Atomic Orbital) B3LYP/6-311+G(2d,p) calculated chemical shifts of tautomers of 1-3 are compared in Table 2 with selected experimental ${ }^{15} \mathrm{~N}$ and ${ }^{13} \mathrm{C}$ chemical shifts. This level of calculation is suitable for organic molecules of medium size and recommended in the pioneering work by Cheeseman et al. [17] focused on the comparison of different models for calculating nuclear magnetic resonance shielding tensors. Additional theoretical verification of some of the values can be found in Table S2. The dominance of the keto structure is consistently reproduced at this level of calculation and agrees reasonably with reported experimental data (corroborates the existence of keto structures in the DMSO solution). The values of the calculated coupling constant ${ }^{1} \mathrm{~J}\left({ }^{15} \mathrm{~N},{ }^{1} \mathrm{H}\right)$ for keto tautomers of compounds $\mathbf{1 - 3}$ are of the normal order of $90 \mathrm{~Hz}$ and are negative in sign $(-95.8,-92.1$ and $-96.7 \mathrm{~Hz}$, respectively); the theoretically predicted values for $\mathbf{2}$ and $\mathbf{3}$ are slightly smaller than the experimentally determined but the difference between the two values are of the correct order and larger for the nitro substituted derivative $\mathbf{3}$. However, as the calculated value for $\mathbf{1 k}$ is slightly larger than that for $\mathbf{2} \mathbf{k}$ one could speculate that a larger value than the experimental value for $\mathbf{3 k}$ (101.4 Hz) should be used in case of $\mathbf{1}$. This is also supported by the calculated NH bond lengths (Table S3). For $\mathbf{1}$ a slightly shorter bond length is calculated than for $\mathbf{2}$ and a shorter bond length is normally associated with a larger ${ }^{1} \mathrm{~J}\left({ }^{15} \mathrm{~N},{ }^{1} \mathrm{H}\right)$ [18]. However, the fine details are less clear as the calculate value for $\mathbf{1}$ is less than that for $\mathbf{3}$ so this has to be investigated further. 
Table 2. Experimental and calculated ${ }^{13} \mathrm{C}$ chemical shifts, ${ }^{15} \mathrm{~N}$ chemical shifts and coupling constant ${ }^{1} \mathrm{~J}\left({ }^{15} \mathrm{~N},{ }^{1} \mathrm{H}\right)$.

\begin{tabular}{|c|c|c|c|c|c|c|c|c|c|}
\hline & \multicolumn{3}{|c|}{1} & \multicolumn{3}{|c|}{2} & \multicolumn{3}{|c|}{3} \\
\hline & \multirow[t]{2}{*}{ exptl* } & \multicolumn{2}{|c|}{ calcd } & \multirow[t]{2}{*}{ exptl* } & \multicolumn{2}{|c|}{ calcd } & \multirow[t]{2}{*}{ exptl* } & \multicolumn{2}{|c|}{ calcd } \\
\hline & & $1 \mathrm{k}$ & $1 \mathrm{e}$ & & $2 \mathrm{k}$ & $2 \mathrm{e}$ & & $3 \mathrm{k}$ & $3 e$ \\
\hline \multicolumn{10}{|l|}{$\delta\left({ }^{15} \mathrm{~N}\right)$} \\
\hline $\mathrm{N}_{\alpha}$ & -207.7 & -206.5 & 30.2 & -202.8 & -201.9 & 46.7 & -218.2 & -209.8 & 27.4 \\
\hline $\mathrm{N}_{\beta}$ & -26.7 & -26.4 & 132.0 & -18.6 & -15.8 & 104.3 & -29.8 & -21.9 & 118.1 \\
\hline$\underline{\mathrm{NO}}_{2}$ & -12.1 & -6.8 & 1.5 & & & & - & -6.0 & \\
\hline${ }^{1} \mathrm{~J}\left({ }^{15} \mathrm{~N},{ }^{1} \mathrm{H}\right)$ & 96.4 & 95.8 & - & 96.5 & 92.1 & - & 101.4 & 96.7 & - \\
\hline \multicolumn{10}{|l|}{$\delta\left({ }^{13} \mathrm{C}\right)$} \\
\hline $\mathrm{C}_{1}$ & 132.2 & 138.6 & 137.8 & - & - & - & - & - & - \\
\hline $\mathrm{C}_{2}$ & 180.5 & 188.1 & 161.1 & - & - & - & - & - & - \\
\hline $\mathrm{C}_{3}$ & 126.7 & 133.3 & 125.3 & 148.3 & 157.9 & 157.9 & - & 158.4 & 158.9 \\
\hline $\mathrm{C}_{4}$ & 144.0 & 153.6 & 147.4 & 127.7 & 133.5 & 129.6 & - & 138.9 & 133.9 \\
\hline $\mathrm{C}_{4 \mathrm{a}}$ & 128.8 & 135.9 & 134.8 & - & - & - & - & - & - \\
\hline $\mathrm{C}_{5}$ & 129.6 & 136.4 & 135.7 & 156.6 & 163.9 & 152.2 & - & 162.5 & 152.2 \\
\hline $\mathrm{C}_{6}$ & 130.0 & 134.3 & 131.1 & 137.9 & 146.3 & 145.2 & 137.5 & 146.0 & 144.8 \\
\hline $\mathrm{C}_{7}$ & 128.2 & 136.9 & 136.0 & 117.7 & 122.9 & 127.7 & 117.9 & 122.8 & 127.9 \\
\hline $\mathrm{C}_{8}$ & 122.8 & 129.0 & 127.1 & 128.8 & 135.3 & 135.9 & 129.2 & 135.4 & 135.9 \\
\hline $\mathrm{C}_{8 \mathrm{a}}$ & 132.6 & 141.1 & 140.5 & - & - & - & - & - & - \\
\hline $\mathrm{C}_{9}$ & - & - & - & 124.6 & 130.0 & 132.8 & - & 130.5 & 133.4 \\
\hline $\mathrm{C}_{10}\left(\underline{\mathrm{CH}_{3}}\right)$ & - & - & - & 11.7 & 14.6 & 14.5 & 11.7 & 14.7 & 14.5 \\
\hline $\mathrm{C}_{1^{\prime}}$ & 138.6 & 148.2 & 151.7 & 141.3 & 149.0 & 159.5 & - & 146.9 & 152.1 \\
\hline $\mathrm{C}_{2^{\prime}}$ & 135.3 & 141.3 & 154.0 & 116.1 & 123.2 & 135.8 & - & 141.3 & 153.8 \\
\hline $\mathrm{C}_{3^{\prime}}$ & 126.0 & 133.9 & 133.5 & 129.5 & 136.2 & 135.9 & 126.1 & 133.8 & 133.7 \\
\hline $\mathrm{C}_{4^{\prime}}$ & 124.5 & 129.9 & 136.5 & 125.6 & 132.3 & 136.4 & 124.6 & 130.5 & 135.4 \\
\hline $\mathrm{C}_{5^{\prime}}$ & 136.5 & 144.9 & 142.4 & 129.5 & 136.8 & 135.7 & 136.6 & 145.2 & 142.4 \\
\hline $\mathrm{C}_{6}$ & 117.8 & 123.2 & 121.5 & 116.1 & 119.0 & 118.7 & 116.7 & 122.4 & 127.9 \\
\hline
\end{tabular}

* from ref. [9]. 
The investigation of the tautomerism in azodyes and related Schiff bases, existing as tautomeric mixtures, is a difficult task for NMR and UV-Vis spectroscopy, because in both cases the signals of the pure tautomers are unknown. The analysis includes either use of model compounds, approximating the spectral characteristics of the pure tautomers [10], or application of chemometric procedures based on resolution of overlapping bands [15]. In both cases the approximations leads to accumulation of errors. Therefore, in this particular case, it is important to verify the NMR results by UV-Vis measurements at the same conditions. In Figure S5 the absorptions spectra of $\mathbf{1}$ in DMSO at saturated solution (as used in the NMR measurements) and at (concentration conventionally used in UV-Vis spectroscopy) are compared. As seen there are no substantial differences in the spectra, which mean that even if there are concentration effects they are slight in this particular case. The effect of using dried DMSO is also negligible. In Figure 1 the effect of the temperature on the tautomerism of $\mathbf{1}$ is monitored. The heating leads to decrease of the content of the keto tautomer as observed for other compounds from this series [19]. The corresponding structured band at $500 \mathrm{~nm}$ decreases leading simultaneously to slight rise of absorption in the range $420-460 \mathrm{~nm}$. Such spectral changes suggest a broad and low intensive enol form signal, which is, in addition, strongly overlapped with the keto tautmomer absorption. The spectra, possessing slight spectral changes along with strong overlapping between signals of the tautomers, can be processed by using the developed by us chemometric approach with the stipulation for substantial calculational error. The processing results show that at $30^{\circ} \mathrm{C}$ (comparable with the conditions in [9]) $\mathbf{1 k}$ is presented with $85 \pm 5 \%$, which is in reasonable agreement with the NMR results (see previously). The corresponding $\Delta \mathrm{H}$ and $\Delta \mathrm{S}$ values of the process $\mathbf{1 e} \leftrightarrows \mathbf{1 k}$ are as follows $-5.4 \mathrm{kcal} / \mathrm{mol}$ and $-14.3 \mathrm{cal} . \mathrm{mol}^{-1} \cdot \mathrm{K}^{-1}$

The generated from the chemometric procedure individual spectra of $1 \mathbf{e}$ and $\mathbf{1 k}$ from Figure 1 show that the enol form has a broad band with maximum at which strongly overlaps with the keto form peak. This leads to slight changes in the spectra when the equilibrium is 
shifted and consequently generates substantial error in the molar fractions determination. The most important is the band around $400 \mathrm{~nm}$ where both tautomers absorb. This band was assigned in [3], to the enol tautomer, which led to underestimation of the keto tautomer content in isooctane and methylene chloride. The correct values for $1 \mathbf{k}$ are correspondingly $73 \%$ and $82 \%$.

\section{Experimental part}

1-((2-nitrophenyl)diazenyl)naphthalen-2-ol (1) used in this study was prepared by an established procedures [20] and its purity was confirmed by TLC and m.p.

The absorption spectra were measured on a JASCO V-570 UV-Vis-NIR spectrophotometer equipped with a thermostatic cell holder (using Huber MPC-K6 thermostat with precision $1{ }^{\circ} \mathrm{C}$ ) at $25^{\circ} \mathrm{C}$ (unless stated otherwise) by using spectral grade DMSO. For the measurements in saturated solution a specially constructed (Hellma Analytics) cell with thickness of $0.01 \mathrm{~mm}$.

M062X functional [21,22] was used in the geometry optimization of compounds $\mathbf{1 - 3}$. The calculations were performed with the TZVP and 6-31+G(d,p) basis sets using the Gaussian 09 program [23]. Frequency calculations for each optimized structure were performed at the same level of theory. No imaginary frequency was found for the lowest energy configurations of any of the optimized structures. The optimized structure of each compound in the gas phase was subjected to optimization in DMSO (dielectric constant $\varepsilon=46.8$ ). Solvation effects were accounted for by employing the Polarizable Continuum Model (PCM) method [24] as implemented in the Gaussian 09 suite. The optimized structures in DMSO were used for calculations of the NMR parameters in same solvent.

The NMR chemical shieldings of selected tautomeric forms of compounds $\mathbf{1 - 3}$ were calculated at the B3LYP/6-311+G(2d,p) level. The calculated absolute shieldings were transformed to chemical shifts using the reference compound tetramethylsilane, $\operatorname{Si}\left(\mathrm{CH}_{3}\right)_{4}$, for 
carbon and hydrogen atoms and nitromethane, $\mathrm{CH}_{3} \mathrm{NO}_{3}$, for nitrogen atoms: $\delta=\delta_{\text {calc }}($ ref $)$ - $\delta_{\text {calc }}$. Both $\delta_{\text {calc }}($ ref $)$ and $\delta_{\text {calc }}$ were evaluated at the same computational level. The nitrogen coupling constants are given for isotope ${ }^{15} \mathrm{~N}$. PyMOL molecular graphics system was used for generation of the molecular graphics images [25].

\section{Conclusions}

The NMR approach for estimation of the keto tautomer content of 1-((2nitrophenyl)diazenyl)naphthalen-2-ol by using the coupling constant ${ }^{1} \mathrm{~J}\left({ }^{15} \mathrm{~N},{ }^{1} \mathrm{H}\right)$ of the model compound $\mathbf{3}$ has been verified by theoretical calculations. According to them the tautomeric equilibrium in $\mathbf{3}$ is fully shifted to the keto form and the coupling constants of the keto tautomers of $\mathbf{1}$ and $\mathbf{3}$ are practically identical, which makes equation (2), suggested by Lyčka [9], suitable for estimation of the tautomerism in $\mathbf{1}$. The main conclusion is that maximal structural similarity must be provided between the tautomeric compound and its keto form model.

The comparison between the experimental results from NMR and UV-Vis spectroscopy in DMSO shows a reasonable agreement in respect of the tautomeric content of $\mathbf{1}$. In this particular case the difference in the values of the keto tautomer cannot be attributed to differences in the concentration ranges and to the content of water in the solvent, but are most probably result of the accumulation of errors and assumptions in the procedures for their determination.

\section{Acknowledgements}

The generous support from the Swiss National Science Foundation by the SCOPES Program (Tautocrowns Joint Research Project, SupraChem@Balkans.EU and SupraMedChem@Balkans.Net Institutional Partnership Projects) and the Bulgarian National 
Science Fund (access to MADARA computer cluster by project RNF01/0110) is gratefully acknowledged. 


\section{References:}

[1] Adegoke O, Idowu O, Olaniyi A. Synthesis and spectroscopic characterization of 4carboxyl-2,6-dinitrophenylazohydroxynaphthalenes. Dyes and Pigments 2008;77:111-7. doi:10.1016/j.dyepig.2007.03.014.

[2] Adegoke OA. Relative predominance of azo and hydrazone tautomers of 4-carboxyl-2,6dinitrophenylazohydroxynaphthalenes in binary solvent mixtures. Spectrochimica Acta Part A: Molecular and Biomolecular Spectroscopy 2011;83:504-10. doi:10.1016/j.saa.2011.08.075.

[3] Manolova Y, Nedeltcheva D, Antonov L. 4-Carboxyl-2,6dinitrophenylazohydroxynaphthalenes tautomerism theoretically re-explained. Dyes and Pigments 2017;136:663-8. doi:10.1016/j.dyepig.2016.09.027.

[4] Ferreira GR, Garcia HC, Couri MRC, Dos Santos HF, de Oliveira LFC. On the Azo/Hydrazo Equilibrium in Sudan I Azo Dye Derivatives. The Journal of Physical Chemistry A 2013;117:642-9. doi:10.1021/jp310229h.

[5] Olivieri AC, Wilson RB, Paul IC, Curtin DY. Carbon-13 NMR and x-ray structure determination of 1-(arylazo)-2-naphthols. Intramolecular proton transfer between nitrogen and oxygen atoms in the solid state. Journal of the American Chemical Society 1989;111:5525-32. doi:10.1021/ja00197a003.

[6] Liu C, Lynch V, Bard AJ. Effect of an Electric Field on the Growth and Optoelectronic Properties of Quasi-One-Dimensional Organic Single Crystals of 1-(Phenylazo)-2-naphthol. Chemistry of Materials 1997;9:943-9. doi:10.1021/cm9605025.

[7] Salmén R, Malterud KE, Pedersen BF, Reidy PL, Sydnes LK, Sinnwell V, et al. Structures of the Azo Dyes Sudan Red G [1-(2-Methoxyphenylazo)-2-naphthol], C17H14N2O2, and Sudan Yellow (1-Phenylazo-2-naphthol), C16H12N2O. Acta Chemica Scandinavica 1988;42a:493-9. doi:10.3891/acta.chem.scand.42a-0493.

[8] Gilli P, Bertolasi V, Pretto L, Antonov L, Gilli G. Variable-Temperature X-ray Crystallographic and DFT Computational Study of the NH $\cdots \mathrm{O} / \mathrm{N} \cdots \mathrm{HO}$ Tautomeric Competition in 1-(Arylazo)-2-naphthols. Outline of a Transiton-State Hydrogen-Bond Theory. Journal of the American Chemical Society 2005;127:4943-53. doi:10.1021/ja0453984.

[9] Lyčka A. 4-Carboxyl-2,6-dinitrophenylazohydroxynaphthalenes tautomerism NMR reexplained. Dyes and Pigments 2017.

[10] Nedeltcheva D, Antonov L, Lycka A, Damyanova B, Popov S. Chemometric Models For Quantitative Analysis of Tautomeric Schiff Bases and Azo Dyes. Current Organic Chemistry 2009;13:217-40. doi:10.2174/138527209787314832.

[11] Kleinpeter E. NMR Spectroscopic Study of Tautomerism in Solution and in the Solid State. In: Antonov L, editor. Tautomerism: Methods and Theories, Weinheim, Germany: Wiley-VCH Verlag GmbH \& Co. KGaA; 2013, p. 103-43.

[12] Bekárek Y, Rothschein K, Vetešník P, Večeřa M. Estimation of azo - hydrazo tautomeric equilibrium in ortho-hydroxy-azocompounds by N.M.R. Tetrahedron Letters 1968;9:3711-3. doi:10.1016/S0040-4039(00)75523-7.

[13] Lyčka A, Mustroph H. 15N- and13C-N.M.R. Study of Azo-hydrazone Tautomerism of 3methyl-1-phenylpyrazole-4,5-dione 4-phenylhydrazone in dimethyl sulphoxide and pyridine. Journal fuer Praktische Chemie 1989;331:11-4. doi:10.1002/prac.19893310103.

[14] Hansen PE, Bolvig S, Buvari-Barcza A, Lycka A, Moreno JM, Romerosa A, et al. LongRange Intrinsic and Equilibrium Deuterium Isotope Effects on 19F Chemical Shifts. Acta Chemica Scandinavica 1997;51:881-8. doi:10.3891/acta.chem.scand.51-0881. 
[15] Antonov L. Absorption UV-Vis Spectroscopy and Chemometrics: From Qualitative Conclusions to Quantitative Analysis. In: Antonov L, editor. Tautomerism: Methods and Theories, Weinheim, Germany: Wiley-VCH; 2013, p. 25-47.

[16] Gordon PF, Gregory P. Azo Dyes. Organic Chemistry in Colour, Berlin: Springer-Verlag; 1987, p. 95-162.

[17] Cheeseman JR, Trucks GW, Keith TA, Frisch MJ. A comparison of models for calculating nuclear magnetic resonance shielding tensors. The Journal of Chemical Physics 1996;104:5497-509. doi:10.1063/1.471789.

[18] Hansen PE. Methods to Distinguish Tautomeric Cases from Static Ones. In: Antonov L, editor. Tautomerism Concepts and Applications in Science and Technology, Weinheim, Germany: Wiley-VCH Verlag GmbH \& Co. KGaA; 2016, p. 35-74.

[19] Joshi H, Kamounah FS, van der Zwan G, Gooijer C, Antonov L. Temperature dependent absorption spectroscopy of some tautomeric azo dyes and Schiff bases. Journal of the Chemical Society, Perkin Transactions 2 2001:2303-8. doi:10.1039/b106241g.

[20] Burawoy A, Salem AG, Thompson AR. The nature of the internal hydrogen bond. Part I. Tautomerism of 1-arylazo-2-naphthols. Journal of the Chemical Society (Resumed) 1952:4793. doi:10.1039/jr9520004793.

[21] Zhao Y, Truhlar DG. Density Functionals with Broad Applicability in Chemistry. Accounts of Chemical Research 2008;41:157-67. doi:10.1021/ar700111a.

[22] Zhao Y, Truhlar DG. The M06 suite of density functionals for main group thermochemistry, thermochemical kinetics, noncovalent interactions, excited states, and transition elements: two new functionals and systematic testing of four M06-class functionals and 12 other functionals. Theoretical Chemistry Accounts 2008;120:215-41. doi:10.1007/s00214-007-0310-x.

[23] Frisch MJ, Trucks GW, Schlegel HB, Scuseria GE, Robb MA, Cheeseman JR, et al. Gaussian 09 Revision D.01. Wallingford, CT, USA: Gaussian, Inc.; 2013.

[24] Tomasi J, Mennucci B, Cammi R. Quantum Mechanical Continuum Solvation Models. Chemical Reviews 2005;105:2999-3094. doi:10.1021/cr9904009.

[25] Schrödinger LLC. PyMOL Molecular visualization system. Schrödinger; n.d. 


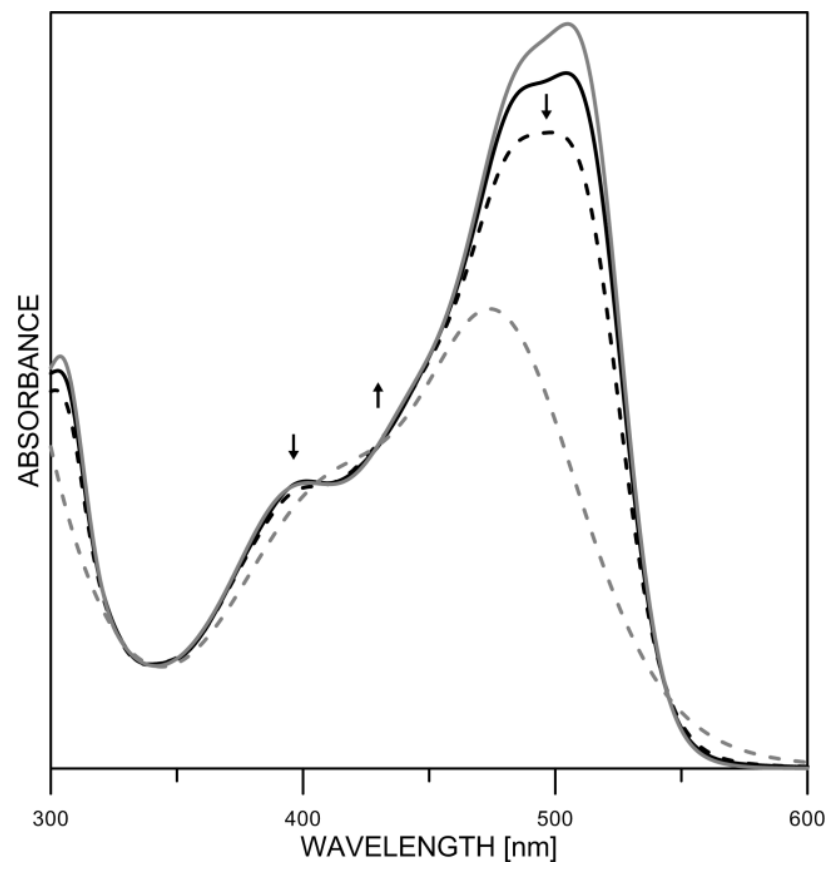

Figure 1. Spectra of 1 in DMSO as a function of the concentration: solid black line $-20^{\circ} \mathrm{C}$; black dashes $-70^{\circ} \mathrm{C}$. The simulated individual spectra of the tautomers are given in grey: keto form - solid line; enol form - dashes. 
Graphical abstract
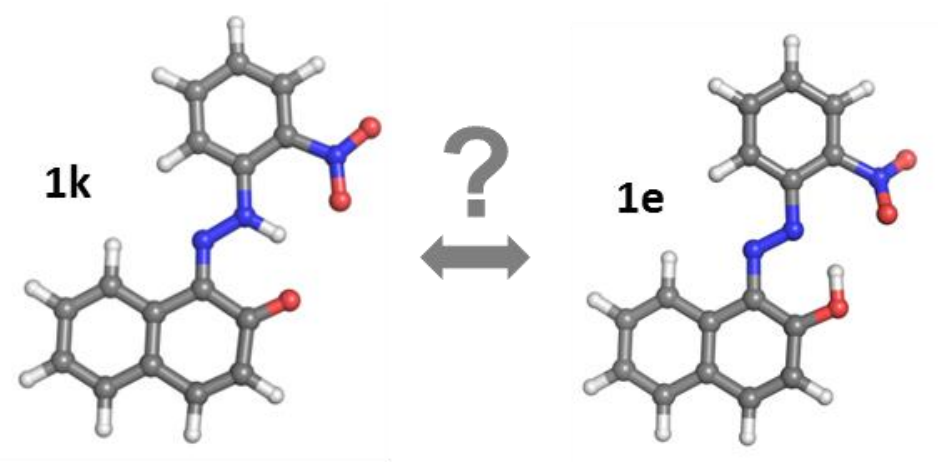